\title{
Implementasi Metode Smart (Simple Multi Atribute Rating Technique) Dalam Menentukan Jurusan Sma Hkbp 2 Tarutung
}

\author{
Article Info \\ Article history: \\ Received 14 Augustus, 2021 \\ Revised 25 September, 2021 \\ Accepted 01 October, 2021
}

\section{Keywords:}

SMART, Major, Decision Support System

\begin{abstract}
Wrong One role of SPK in the field of education is in the decisionmaking process for the selection of majors in high school, which in nature can assist decision makers in providing alternative decisions for appropriate majors for students, where the results of the decisions can be used as material to assist teachers and students in making decisions. Most students only follow friends to follow friends to choose a major so that it allows students to feel unsuitable after entering the major. Therefore we need a decision support system that can calculate the value, ability and personality of students to help determine majors in high school. Smart is a multicriteria decision-making method developed by Edward in 1977. This multi-criteria decision-making technique is based on the theory that each alternative consists of a number of criteria that have values and each criterion has a weight that describes how important it is compared to other criteria. The author uses this method to make it easier to determine the right major, according to the desired criteria. This problem can be classified into problems that are multi-objective (many goals to be achieved) and multi-criteria (many criteria that determine in reaching the decision). The author uses this method to make it easier to determine the right major, according to the desired criteria. This problem can be classified into problems that are multiobjective (many goals to be achieved) and multi-criteria (many criteria that determine in reaching the decision). The author uses this method to make it easier to determine the right major, according to the desired criteria. This problem can be classified into problems that are multi-objective (many goals to be achieved) and multicriteria (many criteria that determine in reaching the decision).
\end{abstract}

This is an open access article under the CC BY-SA license.

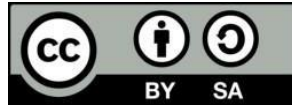

\section{Corresponding Author:}

Selly Marselina Hutabarat ${ }^{1}$, Poppy Waruwu ${ }^{2}$

Nomensen University, Information System, P. Siantar, Indonesia

Email Address: selly22@gmail.com

(C) 2021 The Author: Published by. Cattleya Darmaya Fortuna

\section{Pendahuluan}

Sekolah Menengah Atas adalah jenjang pendidikan menengah pada pendidikan formal di Indonesia [1]. Jurusan di Sekolah Menengah Atas (SMA) digunakan sebagai acuan untuk menyalurkan bakat dan kemampuan dari siswa [2]. Penjurusan pada siswa 
SMA dilakukan ketika siswa berada dikelas $X$ [3]. Penjurusan siswa merupakan hal rutin yang dilakukan pada Sekolah Menengah Atas (SMA) [4]. Penjurusan belajar siswa SMA merupakan pengelompokan minat belajar untuk mempermudah siswa dalam menekuni bidang ilmu dalam pendidikan tingkat lanjut [5]. Penjurusan dilakukan dengan tujuan untuk mengarahkan siswa agar nantinya dapat menekuni bidang tertentu pada level pendidikan selanjutnya [6]. Penentuan jurusan siswa pada tingkat pendidikan sekolah menengah atas pada umumnya menggunakan rekomendasi hasil psikotes, nilai akademik, minat dan bakat siswa. Tidak semua sekolah memiliki data yang lengkap untuk melakukan penjursan siswa [7]. Sistem yang berjalan pada saat ini masih menggunakan Microsoft excel, sehingga membutuhkan waktu tidak sedikit. Selain itu memerlukan tingkat ketelitian yang tinggi, sehingga resiko kesalahan dalam proses perhitungan semakin besar. Resiko Kesalahan dalam proses perhitungan penjurusan siswa berdampak pada hasil pemilihan program studi. Oleh karena itu diperlukan sebuah metode baru yaitu Sistem Pengambilan Keputusan untuk proses penjurusan siswa [8] dengan menerapkan Simple Multi Atribute Rating Technique (SMART). Metode Simple Multi Atribute Rating Technique (SMART) merupakan metode yang dalam penerapannya mempertimbangkan beberapa kriteria dan alternatif yang mampu membantu pengguna dalam menentukan pilihannya dengan lebih tepat sehingga dapat digunakan dalam sistem penunjang keputusan [9]. Untuk melakukan pembobotan Simple Multi Atribut Rating Technique (SMART) dapat dilakukan dengan, mengurutkan kepentingan suatu atribut dari level terburuk ke level terbaik. Implementasi metode SMART dalam sistem pendukung keputusan ini berjalan dengan baik, metode ini dapat digunakan berdasarkan bobot dan kriteria yang sudah ditentukan. Hasil penelitian ini menunjukkan bahwa untuk mendapatkan nilai keputusan harus melalui proses input nilai dan bobot masing-masing kriteria, nilai dan bobot di-input berdasarkan tingkat kepentingan kriteria yang dipilih. Hasil analisis yang didapatkan adalah hasil perangkingan nilai terbesar untuk dijadikan bahan dalam proses pengambilan keputusan [10]. Sistem pendukung keputusan sangat diperlukan untuk dapat menyelesaikan permasalahan ini. Sistem pendukung keputusan merupakan suatu sistem yang mampu memecahkan masalah secara efesian, efektif, yang bertujuan untuk membantu pengambilan keputusan dengan memilih berbagai alternatif keputusan [11].

Sistem pendukung keputusan memberikan suatu keputusan yang bersifat semiterstruktur, dimana tidak seorangpun tahu secara pasti bagaimana keputusan seharusnya dibuat [12]. SPK bertujuan untuk menyediakan informasi, membimbing, memberikan prediksi serta mengarahkan kepada pengguna informasi agar dapat melakukan pengambilan keputusan dengan lebih baik [13]. Sistem pendukung keputusan tidak dimaksudkan untuk menggantikan peran pengambil keputusan, tapi untuk membantu dan mendukung pengambil keputusan [14]. Berdasarkan pengujian yang dilakukan, sistem yang dibuat mampu memberikan hasil yang baik sesuai dengan perhitungan yang digunakan, membantu mempercepat dalam mengambil keputusan [15].

\section{Metode}

SMART merupakan linear additive model untuk meramal nilai setiap alternatif. SMART lebih banyak digunakan karena kesederhanaanya dalam merespon kebutuhan 
pembuat keputusan dan caranya mengalisa respon. Analisa yang terlibat adalah transparan sehingga metode ini memberikan pemahaman masalah yang tinggi dan dapat diterima oleh pembuat keputusan. Model fungsi ulti liniar yang digunakan oleh SMART adalah seperti berikut:

$$
\operatorname{Maximize} \sum_{j=1}^{k} W_{j} \cdot U_{i j}
$$

Dimana :

1. $W_{j}$ adalah nilai pembobotan kriteria ke $j$ dari $k$ kriteria.

2. $U_{i j}$ adalah nilai utility alternatif $i$ pada kriteria $j$.

3. Pemilihan keputusan adalah mengidentifikasi mana dari $\mathrm{n}$ alternatif yang mempunyai nilai fungsi terbesar.

4. Nilai fungsi ini juga dapat digunakan untuk merangking $\mathrm{n}$ alternatif.

Berikut adalah langkah - langkah pengambilan keputusan pemilihan jurusan menggunakan metode SMART:

1. Tentukan kriteria yang digunakan dalam pemilihan jurusan.

2. Tentukan alternatif jurusan yang dinginkan.

3. Rangking kriteria dan berikan bobot berdasarkan kriteria paling penting dan kriteria paling tidak penting. Kriteria paling penting disetkan dengan bobot 100 dan kriteria paling tidak penting disetkan dengan nilai 10 .

4. Cari nilai rata - rata bobot kriteria berdasarkan yang paling penting dan paling tidak penting.

5. Berikan bobot kepada setiap alternatif berdasarkan setiap kriteria. Bobot alternatif dalam skala $0-100$. Nol sebagai nilai minimum dan 100 sebagai nilai maksimum dalam pembobotan alternatif berdasarkan setiap kriteria ini terdapat empat kriteria dimana bobotnya telah di input oleh sistem berdasarkan data yang dimiliki alternatif yaitu kriteria nilai mata pelajaran, nilai test akademik, nilai kepribadian.

6. Menghitung nilai utilitas terhadap semua alternatif berdasarkan setiap kriteria

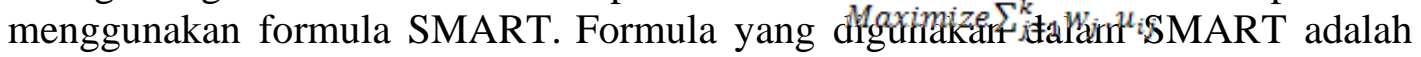
. Nilai Wj diperoleh dari langkah 4 dan nilai Uij diperoleh dari langkah 5.

7. Mendapatkan urutan kepentingan alternatif berdasarkan nilai tertinggi.

Spesifikasi perangkat yang dibutuhkan yaitu:

1. Prosesor Intel Pentium IV 1,8 Ghz

2. Memory $512 \mathrm{Mb}$

3. Harddisk minimal $40 \mathrm{~Gb}$

4. VGA $128 \mathrm{Mb}$

5. Microsoft Word 2007

6. Microsoft Excel 2007

\section{Analisa dan Pembahasan}

Adapun algoritma dari pembobotan yaitu sebagai berikut: 
doi.org/10.54209/jatilima. V3i2.149

\section{Input:}

NBF $=$ Nilai Bobot Faktor

$\mathrm{NEF}=$ Nilai Evaluasi Faktor

$\mathrm{NBE}=$ Nilai Bobot Evaluasi

Output:

$\mathrm{NBE}=$ Nilai Bobot Evaluasi

$\mathrm{TNE}=$ Total Nilai Evaluasi

Proses:

$\mathrm{NBE}=\mathrm{NBF} * \mathrm{NEF}$

$\mathrm{TNE}=\mathrm{NBE} 1+\mathrm{NBE} 2+\mathrm{NBE} 3+\mathrm{NBE} 4, \ldots$.

$\mathrm{Max}=\mathrm{NBE} 1 ; \mathrm{NBE} 2 ; \mathrm{NBE} 3 ; \mathrm{NBE} 4$

\section{Implementasi}

Pengujian sistem menggunakan microsoft word dengan menginputkan Bobot Faktor dan Evaluasi Faktor yang telah ditentukan sebelumnya. Setelah semua data terisi, maka hitung Nilai Bobot Evaluasi. Berikut salah satu data siswa.

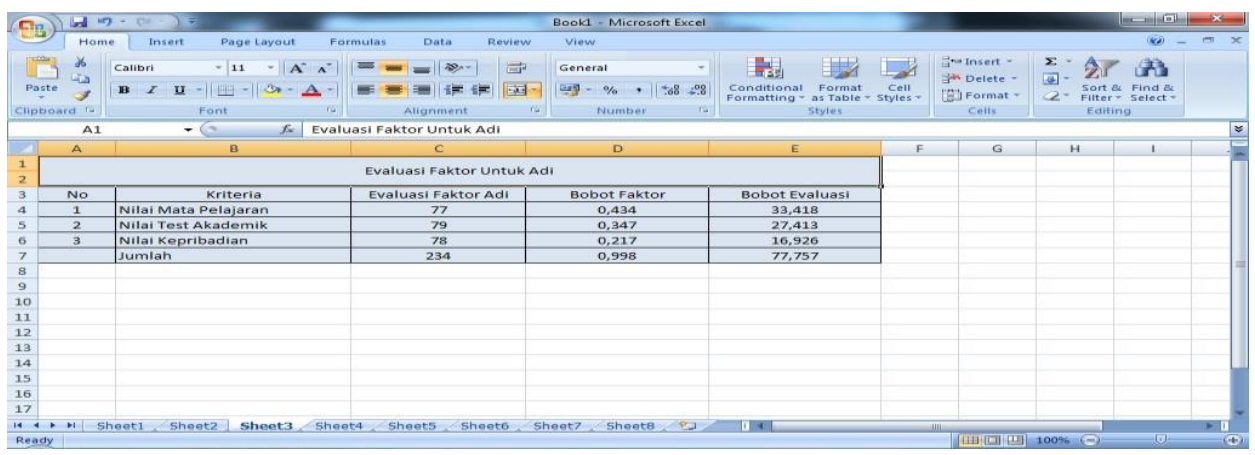

Gambar 1. Design Evaluasi Faktor Untuk Adi

Selanjutnya mencari nilai terbaik dari setiap nilai yang telah ada untuk mendapatkan hasil yang baik, seperti yang ditampilkan pada gambar berikut:

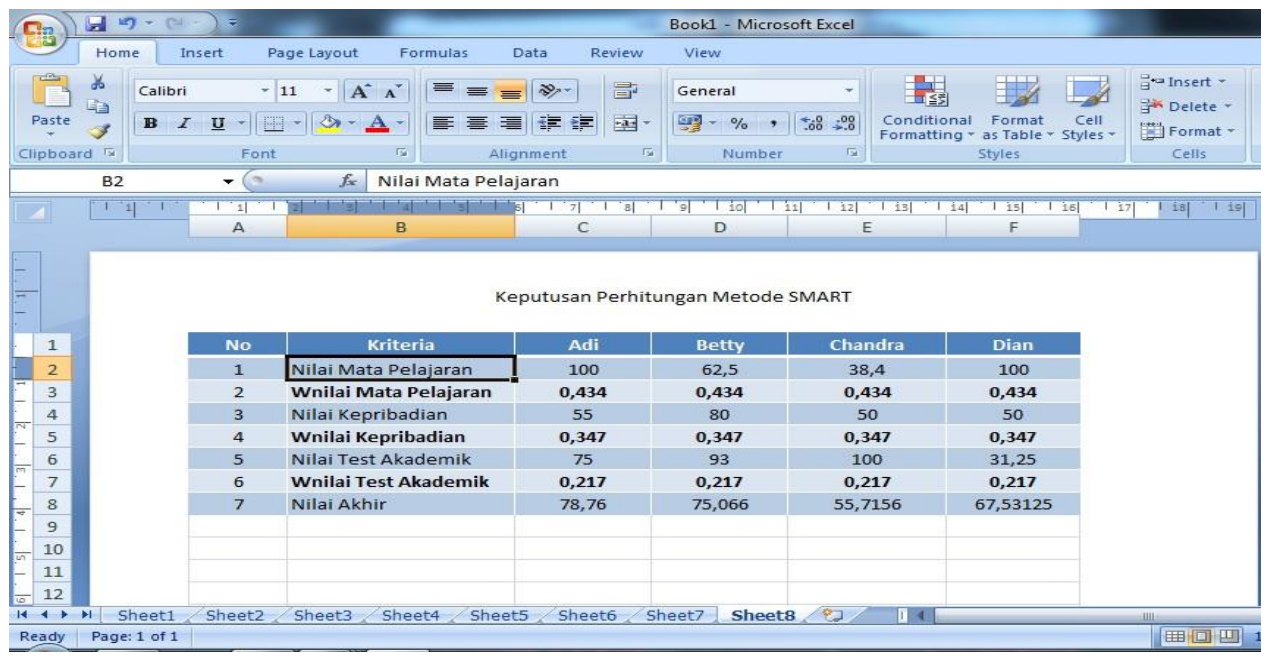

Gambar 2. Design Nilai Terbaik 
Selly Marselina Hutabarat ${ }^{1}$, Poppy Waruwu ${ }^{2}$

doi.org/10.54209/jatilima. V3i2.149

Dari gambar tabel diatas terlihat adanya pengurutan nilai dari nilai yang terbesar ke nilai terkecil. Ini karena jika mereka memperoleh nilai akhir $<7,5$ maka jurusannya adalah IPA dan jika nilai akhir $<7,5$ maka jurusan adalah IPS.

\section{Kesimpulan}

Dengan adanya kesimpulan dan saran ini dapatlah diambil suatu perbandingan yang akhirnya dapat memberikan perbaikan- perbaikan pada masa yang akan datang. Adapun kesimpulan yang penulis peroleh adalah sebagai berikut: Kriteria - kriteria yang digunakan dalam pemilihan jurusan di SMA HKBP 2 Tarutung yaitu nilai mata pelajaran, nilai test akademik, nilai kepribadian sangat membantu dalam membangun sistem pendukung keputusan penentuan jurusan di SMA HKBP 2 Tarutung. Proses penentuan jurusan pada SMA HKBP 2 Tarutung dapat dilakukan dengan mudah karena telah memiliki parameter - parameter yang jelas dalam memudahan siswa untuk memilih jurusan sesuai dengan bakat dan minat dari masing - masing siswa. Sistem penjurusan menjadi lebih objektif dan akurat karena tidak hanya menggunakan nilai mata pelajaran saja melainkan juga aspek - aspek yang mempengruhi dalam menentukan jurusan siswa

\section{Reference}

[1] D. Apriadi and R. Kuswandhie, "SISTEM PENDUKUKUNG KEPUTUSAN PENENTUAN JURUSAN PADA SMA BINA SATRIA," JUSIM (Jurnal Sist. Inf. Musirawas), vol. 5, no. 02, 2020.

[2] R. Kurniasari and A. Fatmawati, "PENERAPAN ALGORITMA C4.5 UNTUK PENJURUSAN SISWA SEKOLAH MENENGAH ATAS," Komputa J. Ilm. Komput. dan Inform., vol. 8, no. 1, 2019.

[3] S. Susanti, D. A. Irawati, and R. Rismanto, "SISTEM PENDUKUNG KEPUTUSAN PENJURUSAN PADA SISWA SMA," J. Inform. Polinema, vol. 3, no. 4, 2017.

[4] T. Y. Akhirina, D. Yulistyanti, A. Rusmardiana, and U. Pauziah, "Pengujian Sistem Pendukung Keputusan Penjurusan SMA di Banten menggunakan Metode Black Box," J. RESTI (Rekayasa Sist. dan Teknol. Informasi), vol. 2, no. 3, 2018.

[5] M. Mughniy, R. C. Wihandika, and B. H. Prasetio, "Sistem Rekomendasi Psikotes untuk Penjurusan Siswa SMA menggunakan Metode Modified K-Nearest Neighbor,” J. Pengemb. Teknol. Inf. dan Ilmu Komput., vol. 2, no. 1, 2018.

[6] I. Y. dkk. Arifiana, "PKM Pengembangan Aplikasi I-PASS Untuk Mengetahui Minat Siswa SMA Diponegoro Ploso Jombang (Berdasarkan Teori Minat Holland)," Community Serv. Consort., vol. 1, no. 1, 2020.

[7] A. R. Kadafi, "Perbandingan Algoritma Klasifikasi Untuk Penjurusan Siswa SMA," J. ELTIKOM, vol. 2, no. 2, 2018.

[8] A. S. Wicaksono, S. H. Fitriasih, and Kustanto, "Sistem Pendukung Keputusan Penjurusan Siswa Sma N 1 Kawedanan Dengan Metode Topsis," J. TIKomSiN, vol. 5, no. 2, 2017.

[9] S. G. Andika, K. Kusnadi, and P. Sokibi, "SISTEM PENDUKUNG KEPUTUSAN PEMILIHAN KEGIATAN EKSTRAKURIKULER UNTUK 
SISWA SMA MENGGUNAKAN METODE SIMPLE MULTI ATTRIBUTE RATING TECHNIQUE (STUDI KASUS : SMA SANTA MARIA CIREBON)," J. Digit, vol. 9, no. 1, 2020.

[10] A. T. P. Utari, M. Yamin, and L. Surimi, "Sistem Pendukung Keputusan Penetuan Status Gizi Buruk Dan Rekam Medik Pada Balita Dan Ibu Hamil Menggunakan Metode Simple Multi-Atribute Rating Technique," semanTIK, 2017.

[11] Sriani and R. A. Putri, "Analisa Sistem Pendukung Keputusan Menggunakan Metode Topsis Untuk Sistem Penerimaan Pegawai Pada Sma Al Washliyah Tanjung Morawa," J. Ilmu Komput. dan Inform., vol. 02, no. April, 2018.

[12] F. I.-R. P. Computer, "Sistem Pendukung Keputusan Penerimaan Jurnalis Menerapkan MultiObjective Optimization On The Basis Of Ratio Analysis (MOORA)," JURIKOM (Jurnal Ris. Komputer), vol. 5, no. 1, 2018.

[13] S. W. Sari and B. Purba, "Sistem Pendukung Keputusan Pemilihan Ketua Danru Terbaik Menggunakan Metode ARAS," Semin. Nas. Teknol. Komput. Sains SAINTEKS 2019, 2019.

[14] Y. Zai, Mesran, and E. Buulolo, "Sistem Pendukung Keputusan untuk Menentukan Buah Rambutan Dengan Kualitas Terbaik Menggunakan Metode Weighted Product (WP)," Media Inform. Budidarma, vol. 1, no. 1, 2017.

[15] M. R. Noviansyah, W. Suharso, D. R. Chandranegara, M. S. Azmi, and M. Hermawan, "Sistem Pendukung Keputusan Pemilihan Laptop Pada E-Commerce Menggunakan Metode Weighted Product," Pros. SENTRA (Seminar Teknol. dan Rekayasa), vol. 0, no. 5, 2019. 